Article

\title{
Proximal Cities: Does Walkability Drive Informal Settlements?
}

\author{
Valerio Cutini ${ }^{1, *}$, Valerio Di Pinto ${ }^{2}\left(\mathbb{D}\right.$, Antonio Maria Rinaldi ${ }^{3,4}$ and Francesco Rossini ${ }^{5}$ \\ 1 Dipartimento di Ingegneria dell'Energia, dei Sistemi, del Territorio e delle Costruzioni, Università di Pisa, \\ Via Diotisalvi, 2, 56122 Pisa, Italy \\ 2 Dipartimento di Ingegneria Civile, Edile e Ambientale, Università di Napoli Federico II, Via Claudio, 21, \\ 80125 Naples, Italy; valerio.dipinto@unina.it \\ 3 Dipartimento di Ingegneria Elettrica e delle Tecnologie dell'Informazione, Università di Napoli Federico II, \\ Via Claudio, 21, 80125 Naples, Italy; antoniomaria.rinaldi@unina.it \\ 4 IKNOS-LAB - Intelligent and Knowledge Systems_LUPT, Università di Napoli Federico II, Via Toledo, 402, \\ 80134 Naples, Italy \\ 5 School of Architecture, The Chinese University of Hong Kong (CUHK), Lee Shau Kee Architecture Building, \\ Sha Tin, Hong Kong; rossini@cuhk.edu.hk \\ * Correspondence: valerio.cutini@unipi.it; Tel.: +39-050-221-7794
}

Received: 31 October 2019; Accepted: 17 January 2020; Published: 21 January 2020

check for updates

\begin{abstract}
The uncontrolled growth of urban areas worldwide is pushing a substantial part of the urban population to the fringes of society, confining them to the unsecure and unhygienic settlements that we call "informal." These settlements lack in intelligible layout and essential services and infrastructures, thus representing a challenging issue for policy makers and urban designers in the development of renewal programs and strategies. In order to support the facing of these issues through an on-site upgrade approach, this paper argues that walkability deeply affects the functioning of informal settlements, so as to propose that they can be identified as "proximal cities," which expresses the idea that the vital space in informal settlements has soft boundaries and follows a fuzzy logic. A quantitative analysis, based on a configurational approach, and a qualitative analysis, focused on the morphologic features of the settlements, have been implemented. A comparison of the results shows that this approach is suitable to provide a deeper knowledge on informal settlement and informal society under the assumption of their strict mutual connection. A primal definition of proximal cities, suitable for describing some properties of autopoietic urban systems, emerges from the evidence-based relationships between their spatial and social features. In this respect, a case study has been proposed and discussed.
\end{abstract}

Keywords: informal settlements; configurational analysis; qualitative analysis; walkability

\section{Introduction}

The notion of informal settlements is among the broadest and most ambiguous in the domain of urban studies. They are commonly defined as unplanned residential areas where housing neither complies with planning and building regulations nor meet any design rule, thus lacking basic services, infrastructures and facilities, and causing inhabitants to live in extremely precarious conditions from several perspectives, constantly exposed to disease, deprivation, and violence [1]. Furthermore, such settlements have generally been growing up in the remains of urban land and increasing their exposition to natural disasters. In the last 25 years, the percentage of the world population living in informal settlements has been expanding at an impressive rate [2], mainly in developing countries.

Aside from other issues, informal settlements, as other autopoietic urban environments, resist being referred to by archetypal patterns, which affects the capacity of professionals to grasp the 
rules driving the life of informal societies (the local communities that live there). In the last decade, researchers in the field have shown that such communities use space atypically if compared to "formal" societies in order to meet their need for mutual cooperation, which has almost been lost in western countries [3].

A novel type of common space, characterized by its being on the line between the public and private spheres, emerges in the frame of the city, hosting social functions (such as trade services, facilities, and recreational activities) as well as personal and private activities (i.e., cooking, hygiene, intimate relationships). Recent studies defined them as "spaces-in-between" to emphasize their ambiguous state. Even though they have been observed in the last few years by both qualitative and quantitative methods, spaces-in-between are still under-investigated [4], mainly due to the hurdles they oppose to conventional tools, which are related not only to the lack of spatial patterns but to the intrinsic incoherence of forms, the vagueness of land use, and the complexity of informal society that use them.

This paper, combining qualitative and quantitative analysis methods [3-5], proposes to consider the urban space as generative of human phenomena in the city, so as to investigate spaces-in-between as the primary principles of informal society. It implies that informal settlements are composed of a number of local entities characterized by soft borders, where urban life takes place regardless of the global structure of the informal environment as a whole. The informal life is therefore considered as a life "in proximity," in that it is fully spent and fulfilled within a short radius around home. Such an assumption creates a complex and highly dynamic patchwork that is only vaguely supported by the global structure of the settlement, decisive in its functioning as a distinct entity in the frame of the whole city.

Since walking is a multidisciplinary activity, the metrics to measure places' walkability and its notion itself are very different, causing disagree among researchers and practitioners [6]. Therefore, the way of defining walkability is here paramount.

In urban design literature, attention is focused on the connection between street-level urban design and human environmental perception. Basically, most of the studies in the field simply assert the importance of spatial qualities, such as centrality and regularity, neglecting to attempt their objective definition [7].

Urban elements—open spaces, streets, and squares—seem to play a crucial role in influencing human activities and social interaction [8,9], so that walkability could be regarded as the aptitude of an urban space to foster pedestrian movement-that is to say, an intrinsic property of the urban environment concerning social interaction [10].

Predicting or interpreting the distribution of pedestrian movement in the city is therefore directly related to the walkability of its neighborhood and streets and considered as a quantitative approach. In this sense, the spatial properties of an urban grid have proven to consistently correspond to walking levels [11-13] as an outcome of the comprehensive approach that, within the configurational analysis of urban network, connects urban form, located activities, and pedestrian movement [14]. In such a view, if we assume walkability as depending on the structure of the city, a sharp distinction between its objective and subjective aspects tend to fall off, since the spatial features and the social elements influence each other to create the city as one thing.

The configurational analysis of the urban environment proved its reliability in defining the local and sub-local structure in the city, so as to depict human settlements as hologrammatic entities, where parts and the whole are strictly connected and are visible in each other. In this view, form and function in the city appear as one thing, being different expressions of the complex system of physical and social relationships that underlie and give life to the city. Such an approach allows for city understanding to be translated into numerical terms, fostering the design of more effective upgrade strategies focused on "on-site" approaches [15].

Thanks to the configurational approach, some deeper knowledge of the autopoietic processes that structure informal settlements could be provided in order to highlight the intrinsic order that they 
appear to comply with. This paper aims to foster the comparison between objective, non-discursive, quantitative analysis, qualitative description, and narration of the settlements from dia-chronic and sin-chronic perspectives in order to achieve a primal definition of the proximal city, stressing the notion of walkability in order to unveil the hidden structure of informal settlements.

In practical terms, the integrated use of a configurational approach-based on space syntax techniques-and a qualitative approach — based on the analysis of urban morphology, the observation of the urban geometric pattern, and the shape and arrangement of blocks and buildings-will be used to highlight the very features that characterize informality, even if they are concealed under apparent disorder.

To this aim, the settlement of Baseco, located in the heart of the metropolitan area of Manila (Philippines), is proposed as a case study in order to implement this methodological frame.

The paper is structured as follows: Section 2 contains the theoretical frame of the research, Section 3 presents the methodological framework of the proposed approach, Section 4 presents and discusses the implementation of the method to the case study, Section 5 collects the main results of the work, and Section 6 discusses the results and adds some brief conclusions on the work and its future developments in short and mid-terms.

\section{Theoretical Backgrounds}

In this section, we provide the overview of theoretical premises that our work is based on. Relevant literature in our domain of significance is reported, with a focus on the notion and main features of informal settlements, as well as on the configurational approach that goes under the name of Space Syntax.

\subsection{Informal Settlements}

The largest part of current urban growth is taking place in the so-called developing countries, while most urban theories have been rooted in the developed areas of the world [16]. This is a paradox that affects the approach to the informality of cities and settlements, one of the key themes of the current urban design and policymaking debate.

Traditionally, we are familiar to a limpid dichotomy of formal and informal urban environments, considered as immiscible sectors, while research in the field shows that informality is rather a mode of urbanization [16], mainly characterized by the neglecting of any regulation. From this perspective, urban informality appears to be the cultural product of an informal society rather than the mere leftovers of a richer formal society. Evidence of this assumption can be found in second and third world cities, where informal housing and the land market involves all social classes, from poor to elite [17].

In the last 20 years, examples of urban informality could be found anywhere, albeit with strong differences from case to case ([18-22] and many others). When they occur in developed countries, usually, we are more prone to call them autopoietic settlements, relegating the concept of informality to slums and marginal human settlements [23].

From this point of view, informal settlements are characterized by the lack of congruence between the design of their patterns (streets, squares, and other open spaces), the shape of their architectural objects (houses and other buildings), and recognized urban archetypes (hippodameian, radial, or other rational schemes to organize life in the city) - what we call order, pattern, and rules in the structure of a settlement [24]. At the same time, they lack in services, road paving, and public buildings, resulting in insecurity, unsafety, and insalubrity $[1,2,25]$.

Nevertheless, physical features are not the most interesting and fascinating elements of informal settlements: as a cultural product of informal society, such settlements deal with what is called an informal economy [26] and a related "informal philosophy of life" [25].

Within this conceptual framework, a transdisciplinary approach has been flourishing in the last years. It relies on the idea that the hierarchy of urban needs in informal settlements, related to their informal economy, poor access to a limited stock of resources, and high exposure to any kind of 
uncertainties, which affects its urban and functional structure [5], and it is likely to support a social framework made of inclusive local nuclei $[3,4,15,25]$. They can be considered to be social groups hanging between the family sphere and the public environment, close knit by their capability to meet individual needs in informal settlements.

We call the material form of this social entity "spaces-in-between" [2,15], to express their treading a fine line between public and private domain. Albeit completely unknown in the present formal city, "spaces-in-between" appear to have been familiar in a not so distant past, when some significant share of socio-spatial needs was actually present. This was confirmed by recent research on the topological structure of the city as a complex network [25]. In informal settlements, a large part of daily life takes place within spaces-in-between, making them to appear to be among the main urban resources, to be exploited when working in a perspective of "on-site" upgrading. This addresses the issue of slum upgrading through the improvement of the condition of an existing informal settlement and the quality of life of informal communities without their being displaced [27]. Unlike resettlement, on-site upgrading seems both the most humane and least expensive way to support poor communities living in informal settlements, having respect of the delicate balance of their mutual support [28]. Informal settlements turn out to be composed by a complex framework of spaces-in-between [25], which, rather than well-defined urban objects, are to be regarded as domains of urban life characterized by soft limits. An informal settlement can thus be read as a fuzzy overlapping of individual areas of pertinence, which creates the urban hierarchy that drives its actual functioning. Recent researches show that the "measure" that somehow clarifies this complex pattern is under $200 \mathrm{~m}[3,5,25]$. It obviously affects the structure of the settlement as a whole, in order to produce an urban environment where "proximity" is the key quantity, since urban life takes place in a small, throbbing neighborhood-what we call a proximal city. From this perspective, the human co-presence plays a crucial role, determining the deep meaning of proximity in itself, to be thought of as related to the density of social relationships in the local urban environment. As a result, proximity and walkability are directly related, the latter being considered as a prerequisite of material social interaction, as briefly discussed in the following paragraphs.

\subsection{The Urban Environment in Configurational Perspective}

The analysis of urban settlements has been influenced in the last 40 years by the so-called configurational approach, first theorized by Bill Hillier in the mid 1980s [29,30]. Since then, this approach gained momentum, involving worldwide researchers and professionals, expanding its capabilities to develop methods and techniques, as well implementing them to a wide range of urban issues at different scales.

What fundamentally characterizes the configurational approach is the assumption of the urban grid as the primary element that determines the patterns of human behavior. Movement plays a role of interface between the grid and the land use, in that it is leaded by the visual perception of the surrounding spaces and, on its turn, attract activities. The grid configuration provides each single spatial element, as a result of the relationships with all the others, with a specific aptitude for the attraction of movement flows. This aptitude drives movement-seeking activities in the most densely populated urban areas and addresses the movement-avoiding ones in the most deprived and marginalized part of the city. Movement is then recognized as the key element of a large set of urban phenomena [31]. The movement quota that depends exclusively on the grid configuration, and hence is not influenced by the located activities, is called "natural" as an inner property of the spatial layout. As a result, the spatial layout, thanks to its decisive role in the distribution of movement and in the location of activities, can be assumed as an explanatory variable of the system, also affecting the activities' location. Such logic puts the space of an urban settlement in the foreground, decisively influencing the material and immaterial phenomena that occur along its paths. A further conceptual pillar of the theory is the essential importance of the relations between the spatial elements of the grid-it is then the set of relations within the grid that defines land use patterns and drives the location of activities due to the distribution of movement flows. 
To summarize, the configurational perspective recognizes the relationships among the spatial elements of the grid as the very elements that define the inner logic of a settlement. Conversely, it refers to morphological features-the geometric arrangement of blocks and buildings—as the way an urban environment appears. The capability of configurational analysis to keep these two levels divided is paramount to analyze patterns where there are no strict connections between geometry and topology, as in the case of informal settlements.

\subsection{Walkability and the Topological Structure of the City}

The pattern and distribution of walking movement in the urban environment is a key factor of city function [32]. Nonetheless, the relationship between the syntactical properties of street design and walking behavior is still largely under-investigated [33], although many studies have shown that local and global relational properties in an urban layout play a decisive role in explaining pedestrian movement [33].

According to a configurational approach, Space Syntax theorizes and statistically proves that a significant portion of urban pedestrian movement is not only influenced by, but even determined by, the topological structure of the city [14]. For this reason, the local, intrinsic properties of spaces are not important in themselves but for their relationships to the larger scale structure; in other words, it is the relationship between global and local properties-how the geometric features of each space are related to the configurational pattern of the whole grid-which drives the largest part of walking behavior [14].

Many authors found a narrow correlation between configurational measures and walking activity in urban areas [34-37], so as to allow those parameters to be metrics to estimate the walkability of urban layouts. Under this view, walkability itself could therefore be regarded as an inner property of urban environment, depending on its local layout in the frame of the global structure of the city as a whole.

Indeed, the configurational theory lays on the idea that the city is one thing, interpreting its physical and social layers as different expressions of the same entity; assuming the human perception of urban environment as the cornerstone of city functioning, a movement economy governing the largest part of urban phenomena. All that derives from social interaction is based on human co-presence and is related to walking activity as a prerequisite [31], what makes walkability one of the key aspects of the configurational theory, as already reported in the literature [37].

This paper will not enter the wide scientific debate on the notion, nature, and matter of walkability; it will rather assume walkability as a spatial resource directly related to the relational features of the grid, which a configurational point of view can bring to light as a fundamental intrinsic property of urban settlements.

\subsection{The Space Syntax Approach to Informal Urban Environment}

Within the frame of configurational analysis, several operational techniques have been developed, distinguishing each other for the different way the urban grid is to be reduced into a system. The axial analysis, the first and probably the most used among them, studies the axial map, that is the set of longest and fewest lines that, mutually intersected, cover the whole grid [29]. The observation of the mutual relationships between spatial elements allow to determine a full set of numeric parameters, the configurational indices, which describe the configurational properties of each element, and, all together, represent the configurational state of the system. Axial Analysis, such as other space syntax techniques and tools $[29,31,38-41]$, have been applied to study planned and autopoietic cities and urban patterns worldwide. However, the use of configurational analysis to study informal settlements is largely underdeveloped [4]. A small set of studies are focused on the understanding of the functioning and dynamics of this kind of urban environment in the frame of the contemporary city, even if some interesting results have been obtained by implementing space syntax techniques [3,5,25], fostering 
their capability to make the complex relationships between urban spaces at different scale to arise [41]. Preliminary results in this field seem promising [25].

As an intrinsic configurational property, walkability can be reproduced by means of configurational indices—in particular, integration and choice [31] — which are suitable for highlighting the social and interactional potential of urban spaces, both at the global and local scale. In this paper, the distribution of local integration, global integration, and global choice, as well as the relationships between local and global scale in the city as a whole, will be used to explore the matter, as detailed in the following section.

\section{Materials and Methods}

In the following section, our framework to analyze and understand how informal settlements work is described. Space Syntax techniques and qualitative analysis tools used are briefly introduced in order to let us comparatively discuss the form and function of the informal urban environment in the conceptual frame of the proximal city and the walkability of urban spaces.

Space Syntax is the general theory leading the new "urban science" based on the analysis of complex urban networks [42]. In the last decades, many techniques based on such an approach have been developed and tested all around the world, providing reliable knowledge on the city as a whole [38]. Among them, the so-called Axial Analysis [29] and the derived Angular Segment Analysis [39] proved to be the most effective tools to analyze space at an urban scale. They focus on urban permeability [41], providing a taxonomy of spatial elements rooted on their attractiveness within the generalized movement in the city [31]. It largely proved to be a reliable proxy of prime urban phenomena. The same techniques are used in this paper to provide quantitative data on informal settlements.

Axial Analysis and Angular Segment Analysis, as operational space syntax techniques, are based on the idea that the city can be modelled as a non-random network, composed of nodes ("lines" or "segments") representing urban spaces. The configurational theory of the urban environment assumes, in fact, that a city can be modelled as a network with scale-free properties [43], devoid of the homogeneous distribution of degree that characterizes random networks [44]. In such networks, structures and processes tend to similarly occur across scales so as to promote the emergence of few nodes provided with many links to other nodes on the network (the so-called hubs) and a very high number of nodes with few links [45]. As a result, cities are polarized on a small set of critical nodes, similarly to what happens with social networks, and such distribution is represented by some measures of centrality, suitable for accounting for several urban phenomena.

Space syntax has a distinctive way to generate the urban network, deeply affecting the meaning and computing of the centrality indices; it is known as the "dual" [42] system, in order to distinguish it from so-called "primal" urban networks, based on the use of road-center lines as edges of the urban network [46].

The dual networks making process derives from the fragmentation of urban open space (which includes all the freely accessible areas of the city) into the minimal set of fattest convex spaces and then on the tracing of the minimal set of lines crossing all those spaces [47]. As a result, the dual network inverts the intuitive and common categories of urban networks, since the crossing lines are the nodes of the urban graph, while the junction are its edges [29,42]. In order to be analyzed by Angular Segment Analysis, an urban network has then to be further fragmented in every junction to reach smaller lines known as "segments" [39]. The process could be performed automatically by the use of algorithms emulating the entire process [42] within a comprehensive software [48,49]. Since the dual network is a purely topological urban graph, space syntax provides numerical but non-Euclidean outcomes, which could be attributed to physical urban elements as local properties. It encourages research to develop software and plug-ins to standardize the process and minimize biases in the results [50]. The latest trend in such research is to integrate analysis tools into the GIS environment in order to benefit of its post-processing capability as well to collect and harmonize data from different external sources. This paper uses an ArcGIS [51] software add-on relying on DepthmapXnet [49], 
which collects configurational indices as numerical attributes into a geographical database. It allows users to dynamically visualize the distribution of centrality indices in GIS software and analyze them with statistical post-processing tools, as well with specific configurational tools such as the so-called "Background Patchwork Analysis" (BPA) [38]. This latter is a suitable technique to visualize and interpret how much fragmented the local structure of an urban pattern is, so as to account for the reason why several urban phenomena happens, although there is not a direct statistical correlation between them, as it is for configurational indices [38].

One of the most important benefits of the GIS eco-system for this research is the capability to collect qualitative data into the same frame. In this case, we base the qualitative analysis of informal settlement on the recognition of urban patters that are homogeneous under the following taxonomy: pace of urban blocks, arrangement of blocks and buildings, building density, and typology of building (form). These attributes are stored as local properties of polygons representing the extent of homogeneous areas. Other supporting information is predicted to be useful to verify assertions, like surveys and other qualitative data, and should be stored in the same relational database.

This allows spatially coherent qualitative and configurational data, collected in the same environment and so more easily and consistently usable, to perform comparative analysis based on the pairing of alphanumerical attributes, as is the case in this paper.

To summarize, a quanti-qualitative approach will be adopted in order to make the properties of informal urban environment to arise. Primarily, the topological properties of the urban grid are calculated by means of space syntax techniques, and in particular, Axial Analysis [29] and Angular Segment Analysis [39]. As a result, the walkability potential of the urban environment appears to be reproduced by means of segment local integration. The connection between the global and local scale on the urban network is then explored by observing the comparison and statistical correlation between local and global integration and choice indices. Finally, the Background Patchwork Analysis is used to provide a concise view of this relationship. Once the grid was quantitative analyzed, making its critical properties numerically arise (referred to the main aspects—such as space-in-between, walkability and proximity-here assumed as constituting the informal settlement), a qualitative perspective is adopted in order to provide visible confirmation with reference to the urban morphology and social activities. The urban morphology (the way blocks and buildings are shaped and mutually arranged to compose the urban texture) is in fact regarded as a material, visible and concise indicator of the spatial choices a community makes to organize its inner interactions and meet its own needs.

Applying such methodology, the quantitative properties of the spaces-in-between are highlighted by means of the distribution of walkability potentials on the urban network in order to meet the hypothesis of informal settlements as proximal settlements driven by pedestrian movement and social co-presence. The qualitative confirmations are considered paramount to reinforce the topological results and to attest to the reliability of the assumption of the city as a configurational entity, which is consistent with scientific literature in the field [29,31,41,42]. An implementation of the method is presented in the following section.

\section{Case Study}

In this section, we provide a case study showing the comparison between structure and form in the informal settlement of the BaSECo compound in Manila, which is recognized worldwide as one of the most discussed, critical, and complex informal urban areas. To that aim, the analysis has been performed according to the methodological approach introduced above. The results are provided and discussed in Section 5.

\subsection{Manila and BaSECo: An Intense and Often Uncontrolled Urbanisation}

In Metro Manila, rapid changes of the urban structure have led to an explosion of two opposite yet related phenomena: the development of high-density clusters of high-rise buildings and the formation of dispersed patterns of informal settlements. Over the years, Manila has undergone alternate phases 
of crisis and economic growth, but the urbanization of its territory has continued uninterrupted, following no specific spatial order. Rather, urban growth has been marked by highly volatile and chameleon-like configurations [52]. Large areas of the city, especially in the downtown area, are occupied by informal communities that will be affected by the city's undergoing redevelopment. The Pasig River Rehabilitation Program, a long-term plan to improve water quality and to promote urban renewal, will bring dramatic shifts in the spatial pattern of the urban structure, resulting in the relocation of large sectors occupied by informal communities. Under this program, the district of BaSECo, one of the densest informal settlements in Manila, was selected as a priority area for substantial urban renewal. BaSECo is the name of a little urban area lying on the banks of Pasig River, connected to the mainland of Manila by a little panhandle (Figure 1). As the main city of Philippines, Manila is a major Asian metropolitan area and the 18th largest urban agglomeration in the world. In the last 20 years, it has been experiencing a real flourishing, although $35 \%$ of its 14 million population live in uncertainty in what we call slums or informal settlements. In this frame, BaSECo truly "appeared" in the late 1950s as a Bataan Shipyard and Engineering Company service area, from which it takes its name as an acronym. In the following decades, BaSECo was extended as a flood protection barrier, using the waste from the Manila port. Today, it has an extension of more than $0.6 \mathrm{Km}^{2}$ and hosts an official population of 70,000 inhabitants [53], even if unofficial reconstructions estimates a population of more than 100,000, which is underestimated due to the lack of reliable public registries. In the last few years, BaSECo almost doubled in extension (Figure 2) and increased consistently in population magnitude and density [53]. In 2002, it was officially recognized as an urban settlement of Manila and named Barangay (local government unit) n. 649. As a result, Baseco has been included in renewal policies, opening up an international and local debate on strategies and objectives $[54,55]$.

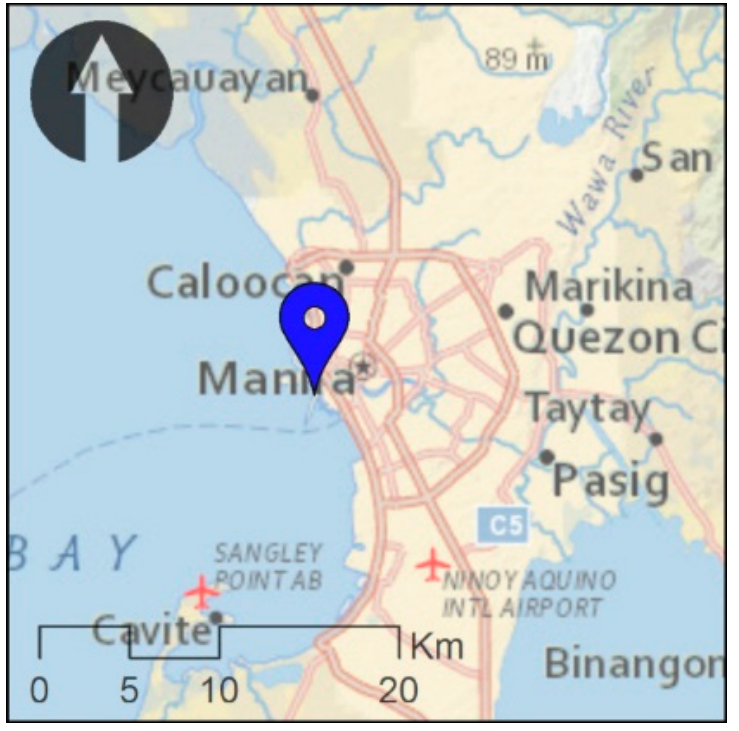

(a)

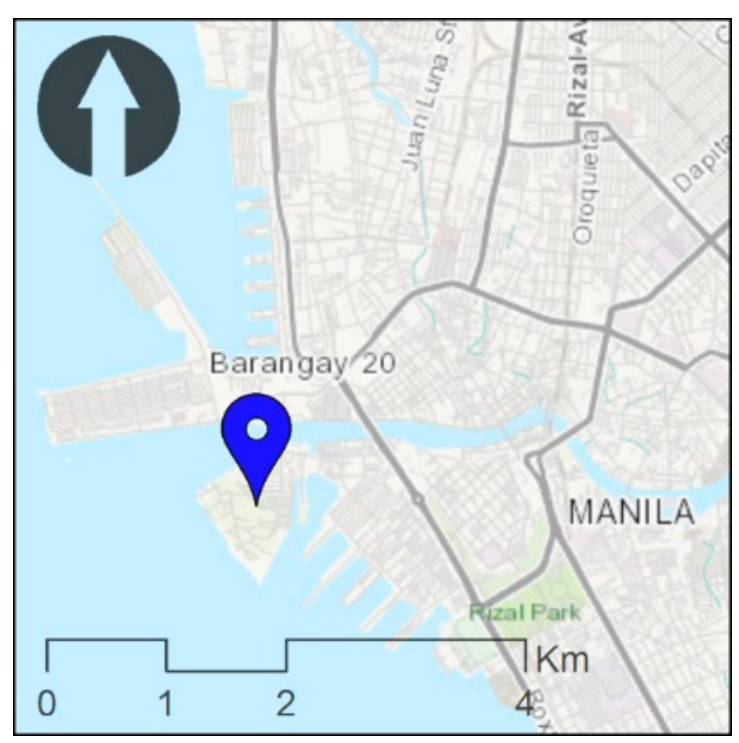

(b)

Figure 1. The setting of BaSECo in Metro Manila: (a) territorial setting; (b) urban setting.

\subsection{BaSECo: Urban Patterns and Open Spaces}

At first sight, BaSECo presents all the typical characteristics of any informal community, such as congestion, poor hygiene conditions, misaligned street spaces and lack of urbanity. The district covers a surface area of approximately 52 hectares; the analysis of the spatial pattern shows a complex urban form where it is possible to identify a critical mass of housing occupying more the $80 \%$ of the entire area. 


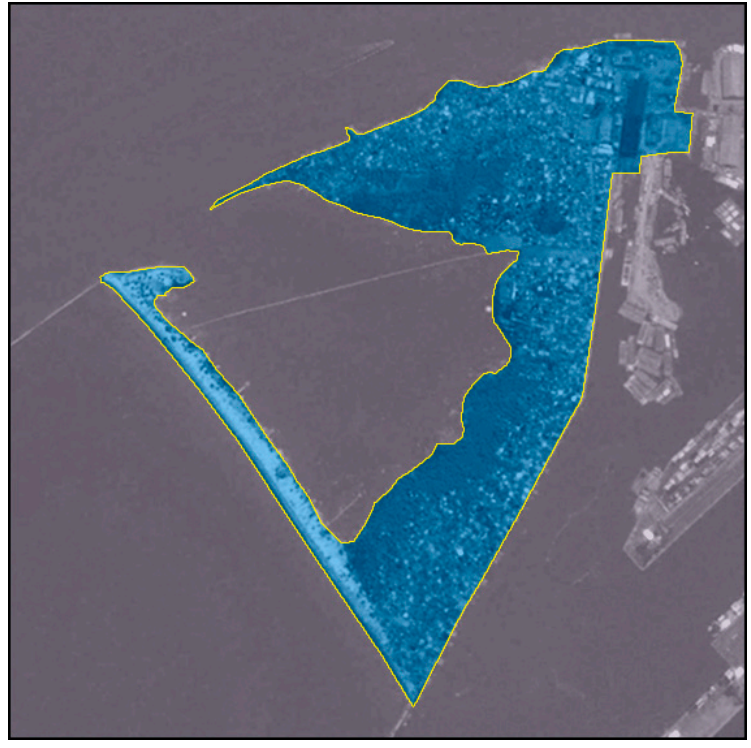

(a)

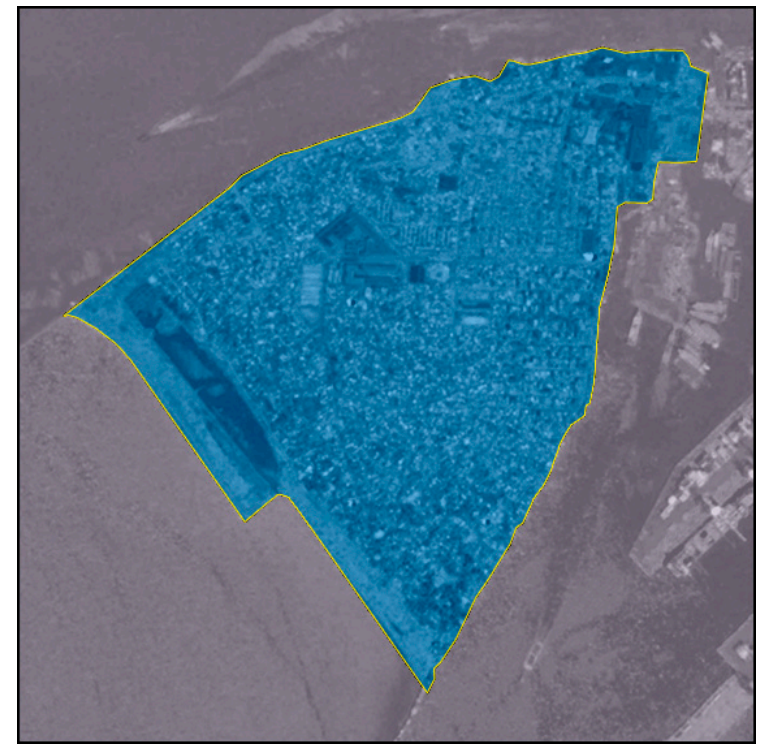

(b)

Figure 2. The evolution in extent of BaSECo compound in the last decades: (a) satellite image taken in 2001; (b) satellite image taken in 2019.

The main street network, which has enough space to allow for the circulation of people and vehicles, covers approximately $100,000 \mathrm{~m}^{2}$, which corresponds to $19 \%$ of the entire surface area. Public facilities, such as markets, schools, the evacuation center, and the church, are located in the central area of BaSECo. The analysis revealed that $65 \%$ of the spatial pattern in BaSECo has an organic configuration. The areas organized in a more regular pattern are the result of a series of fires that arose in the past and are located near the port shoreline and close to the main facilities of the district.

In detail, districts like Gawad Kalinga (GK) and New Site (NS) are characterized by a regular layout that fomented the development of linear communities, in that this type of organization facilitates social interactions in the streets, thereby consolidating a sense of belonging in the residents [56]. By contrast, in the organic pattern of OS (S), neighborhood relations are not so clearly defined, and social interaction occurs among small groups of families because of proximity. This difference in urban layout and community life deeply affects the distribution of configurational indices of centrality, as reported below.

The lack of open spaces and community facilities is a serious issue to be addressed. As introduced above, the unplanned and irregular structure, typical of informal settlements, generates dynamic spaces where distinctions between public and private are not clearly defined. The proximity of people and open space in informal settlements generates a specific relationship "because they are socially produced and constructed" [57]. Such intermediate open spaces are not simply vital to the effective functioning of settlements but, rather, offer a place where social relationships and productive activities can flourish, providing what is perhaps the greatest value to informal communities [56].

\section{Results}

In this section, the main results of the application of the developed methodological frame to the case study are presented. Each outcome will be briefly analyzed with reference to the notions of the proximal city and space-in-between and within the general frame of walkability. A more comprehensive discussion of results will then follow.

\section{Anatomy, Physiology, and Aetiology of BaSECo: Quantitative and Qualitative Outcomes}

Configurational analysis has been implemented, defining the urban network upon a vector-graphics cartography developed by authors that interpret and compare satellite images from 
different public sources (mainly Google maps and Bing maps), as well as using other public services providing geo-spatial data (mainly Open street map). The authors interpreted the map to define freely accessible public space in order to set up the open spaces map of the settlement. Even though it was not possible to conduct systematic and statistically reliable interviews-due to the difficult local context-but only unstructured in-person interviews to individual households, the obtained results appear suitable to support the analysis of images provided by public services (mainly Google street view). The resulting open space map collects the spaces that are actually accessible, highlighting remarkable differences, also in these terms, between urban districts.

To give an example, the North-to-South alleys in Gawad Kialinga have been excluded from open space map because of the presence of fences that forbid public access, while organic patterns in the south of the settlements have complete permeability (Figure 3).

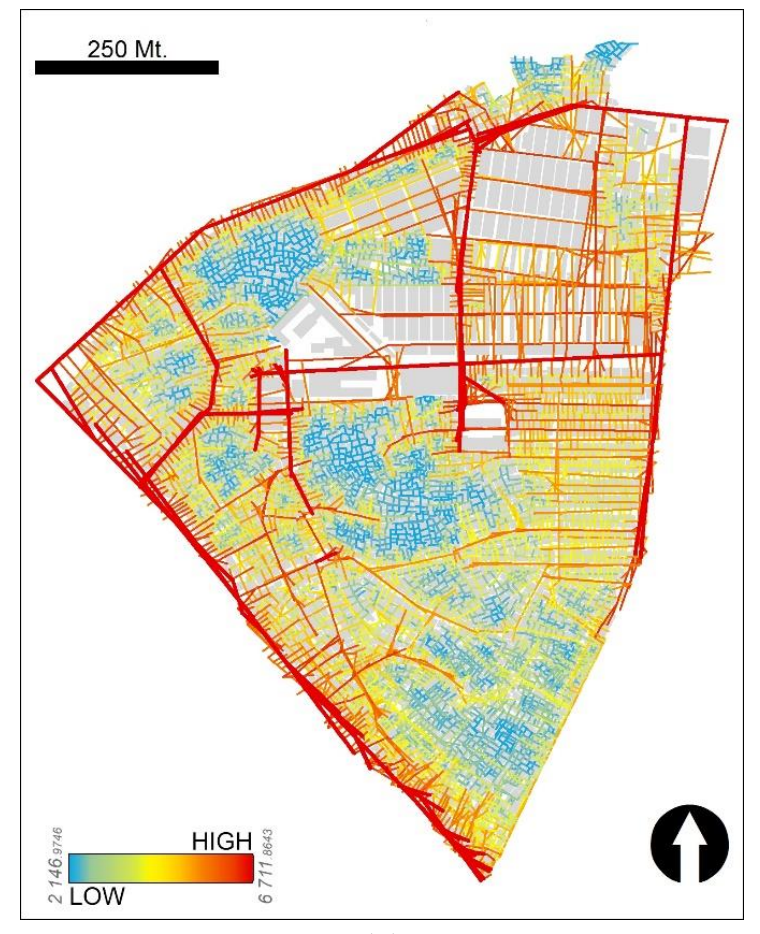

(a)

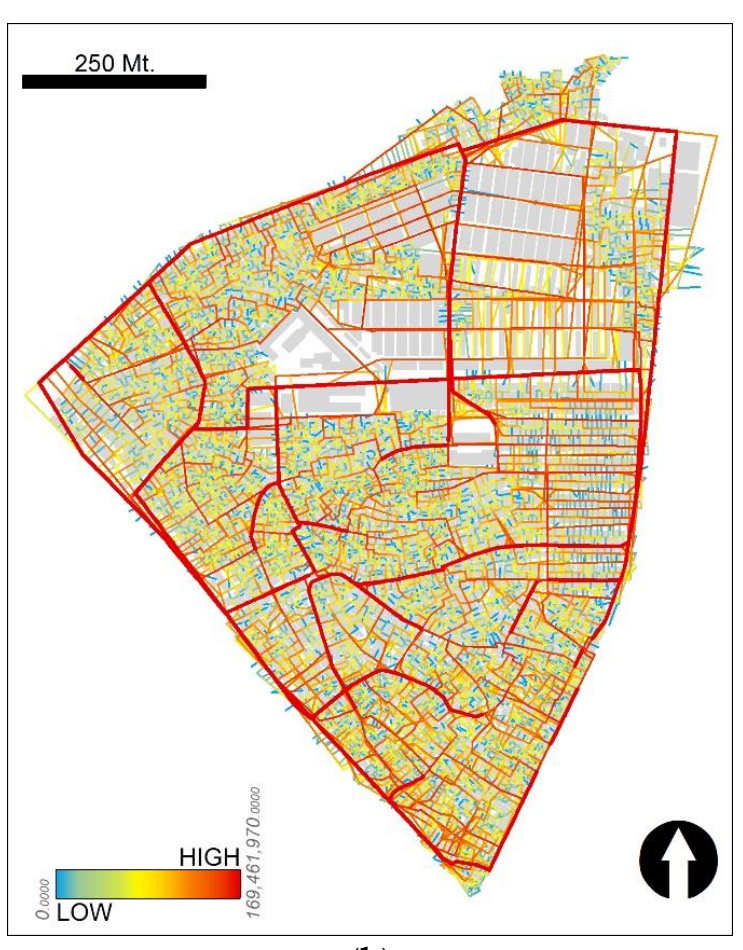

(b)

Figure 3. The global configuration of BaSECo: (a) Global Integration-fat, red lines highlight the so-called "integration core"; (b) Global choice. Light, grey, solid hatches outline closed spaces.

The urban network has been therefore drawn implementing the space syntax algorithm [47], by the use of the DepthMap software package (London, UK) [49]. The resulting network has been analyzed using a plug-in developed by the authors in the ArcGIS environment that implements a Space Syntax techniques algorithm through the depthmapXnet application [49]. In the same GIS environment, qualitative data, derived and collected by the authors from the vector-graphic cartography and the on-site survey, have been stored as a relational geo-database. Qualitative analysis and comparative analysis have been implemented in the same environment.

Focusing on the analysis, it is appropriate to start by saying that BaSECo actually shows a fast-changing morphology due to a labile territory and highly precarious urban assets. As a result, BaSECo has an extremely fragmented urban area lying on an unregulated dynamic. The few public goods and services are strongly polarized and gravitate toward the few suitable public spaces, which are mainly paved streets and small squares. The largest part of the settlement is occupied by small and unpaved streets, which are generally overcrowded and where local services, private houses, and common spaces thicken. Some recent research here recognizes a characteristic form of urban 
environment, typical of informal society, called space-in-between $[2,15]$. Its trace within the urban topology can be made to arise by configurational analysis, as shown below.

In this morphological dynamic, most of BaSECo's open spaces are therefore residual to the complete saturation of areas left free by natural and anthropic disasters or by the expansion of the waste heap. This left a deep trace in the structure of the settlement, as reported by the specifics of dual urban network, which has more than 48,000 lines per $\mathrm{km}^{2}$, a number many times higher than is typical in western cities.

The configurational analysis of BaSECo by means of the space syntax approach and techniques gives rise to a strong taxonomy of urban space, showing a clear polarization of high values of global integration and choice nearby the few paved roads. It is this structure that supports the main movement flows in the settlement and corresponds to what is generally known as the foreground structure [38]. Nonetheless, although the urban system is strongly arranged into a hierarchy, Figure 3 shows that it lacks in a real urban center, since the foreground structure seems mainly to work as a functional support for the settlement, promiscuously used by the main services and shops (Figure 3). Red, fat lines in the map (Figure 3a) highlight the most integrated urban spaces. They mainly appear on the edge of the settlement, near one of the main paved road, while some lines are in what seems to be the geometric center of the urban grid, so as to create a big cross. These latter lines in turn retrace two of the main roads of BaSECo as a whole. The authors interpreted this appearance of the urban system to not be consistent to the so-called "deformed wheel," which is the way a configurational global structure typically expresses the presence of a global centrality [58]. A deformed wheel is composed of a high concentration of the most integrated lines to form a pseudo-orthogonal grid in the center (generally corresponding to the Central Business District-CBD) and some other highly integrated lines on the edge to form the spokes of the wheel. A deformed wheel therefore collects the backbone of the topological structure of the city as a whole, connecting the center to the edge and defining the interstices where less integrated areas can flourish. On the contrary, BaSECo shows most of the highly integrated lines on the edge, reversing the wheel and thus seemingly revealing the lack of global urban centrality.

As a result, the global structure sews up a large set of localities, which are highly fragmented and segregated, but it does not define the patterns where the local structures could express their role in the functioning of the settlement. Conversely, local centralities seem to flourish almost independently from the distribution of global configurational indices, as expressed by Figure 4, which collects the results of configurational analysis at a local scale. A local analysis is the implementation of space syntax algorithms with different restriction to calculation interval, known as local radii (metric and topological steps for the case) [31,39]. The local analysis at $200 \mathrm{~m}$ radius (Figure $4 \mathrm{a}$ ) shows the presence of two main highly integrated urban areas, located in south and northeast of the settlement. The granularity of the local configurational pattern is not clear in the metric analysis due to the excessive gradient between integrated (fat red and orange lines) and segregated (green and blue lines) nodes of the urban graph (Figure 4a). To overcome this problem, a topological analysis has been carried out (Figure 4b), exploiting its capability to reproduce the individual wayfinding experience in the urban environment, which account for the narrow correlation with pedestrian flows [29,59]. The distribution of local integration at topological radius 3 highlights the presence, mainly in the south of the grid, of a high number of well-separated local centralities, consisting of a highly integrated nucleus surrounded by less integrated lines, which seems to provide a quantitative interpretation of the spaces-in-between, consistent with its social meaning $[2,15]$.

To summarize, the configurational analysis of BaSECo shows a complex structure that is dominated by a dense presence of local centralities, which occupy the largest part of the settlement and its most densely populated areas. Since the granularity of the network makes the positional value highly variable on the grid, a fluid order seems to govern the social and physical dynamic of BaSECo, depicting the concept of the proximal city by means of numbers and measures. In this view, walkability seems to essentially drive the functioning and evolution of the settlement, as the predominance of local on 
global scale expresses in terms of topological configuration. These qualities of the local structure of BaSECo are clearly highlighted by means of the Background Patchwork Analysis [38], providing a bi-dimensional graph, where lower peaks on the $y$-axis (local metric mean depth) stand for local centralities, and their position on the $x$-axis (global metric mean depth) expresses their mutual mean topo-geometrical distance. Such representation provides a concise overview of the patterns that are nested in the foreground structure, highlighting the topo-geometric connection between local and global scale in the urban system.

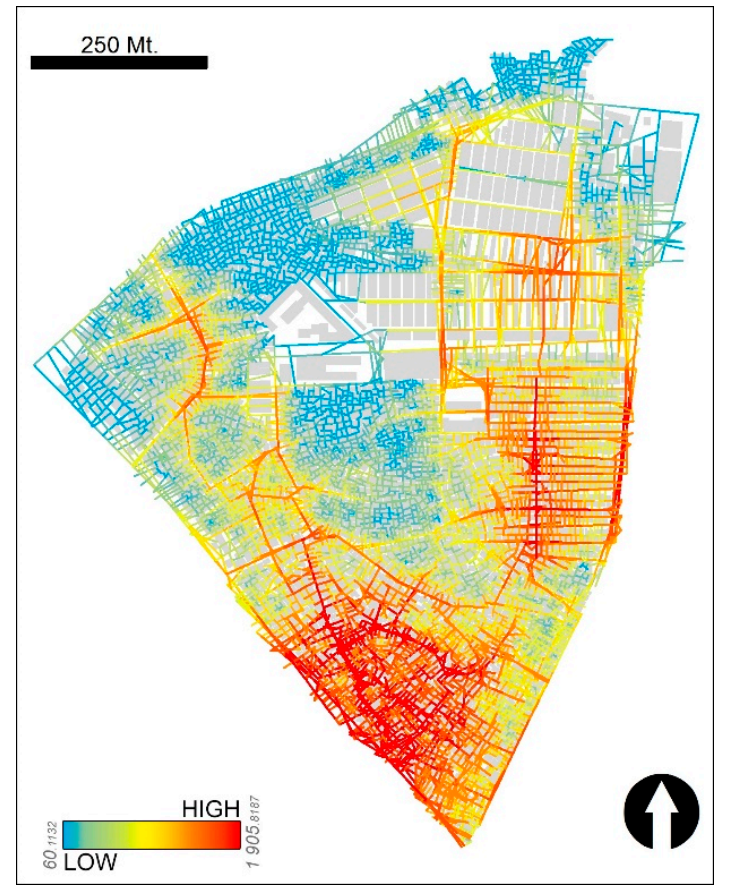

(a)

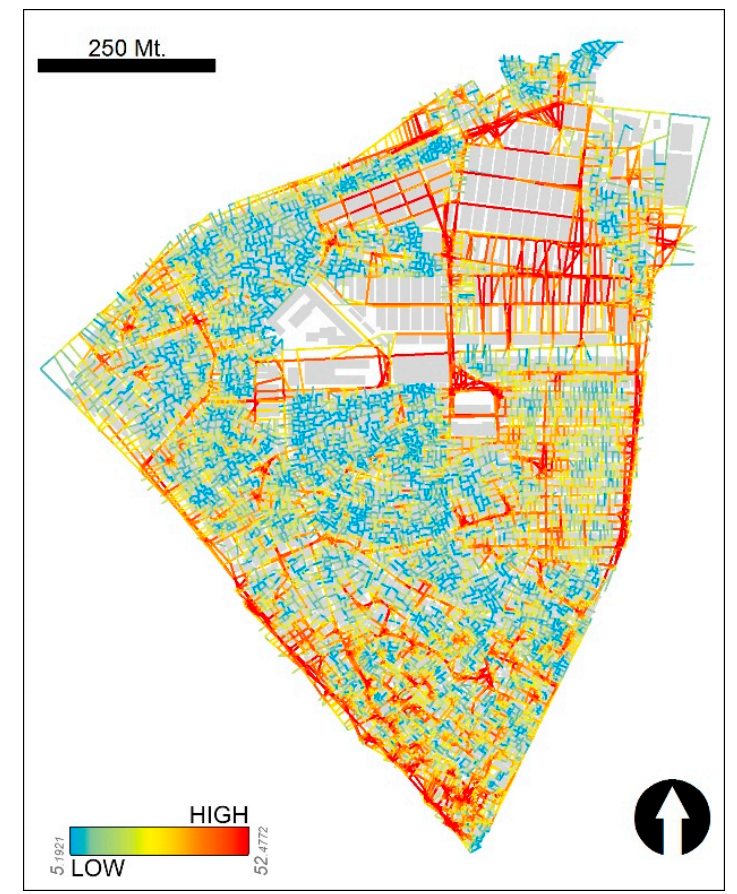

(b)

Figure 4. The local configuration of BaSECo: (a) Local Integration-metric radius 200; (b) local integration-topological radius 3 steps. Light, grey, solid hatches outline closed spaces.

Referring to the BPA graphs, we can compare the properties of the urban network at lowering local metric mean depths. The BPA acquires meaning when its graph consists of a compact block collecting the largest part of the points, representing the lines of the urban grid, from which a set of lower peaks hangs down. It depicts the patchwork of local centralities (the lower peaks) surrounded by a larger set of more or less integrated lines (the block). The measures of the local metric mean depth that correspond to significant BPA graphs can be multiples and are characteristic of each urban environment, since they root in the fragmentation of the urban grid. Under this approach, 200 (Figure 5) and 100 (Figure 6) meters proved to be the most significant metric local depth for the case of BaSECo, since BPA is not more significant as the depth increases (Figure 7). With reference to $100 \mathrm{~m} \mathrm{BPA} \mathrm{(Figure} \mathrm{6),}$ the points constituting the lower peaks correspond to the local, most integrated lines of the urban grid (Figure $4 \mathrm{~b}$ ). The isolation of points in the peaks highlight both a high polarization of topo-geometrical indices and their rapidly decreasing gradient. As a result, peaks in the BPA graph seem to reply in topo-geometrical terms to what we call spaces-in-between, making them clearly visible in the structure of the settlement.

Although it is not statistically related to urban phenomena [38], BPA actually confirms the idea that a very short characteristic distance drives the functioning of the settlement, defining the pertinence of space-in-between as a critical urban element of BaSECo and thus reinforcing the idea of informal settlements as proximal cities driven by walkability. 


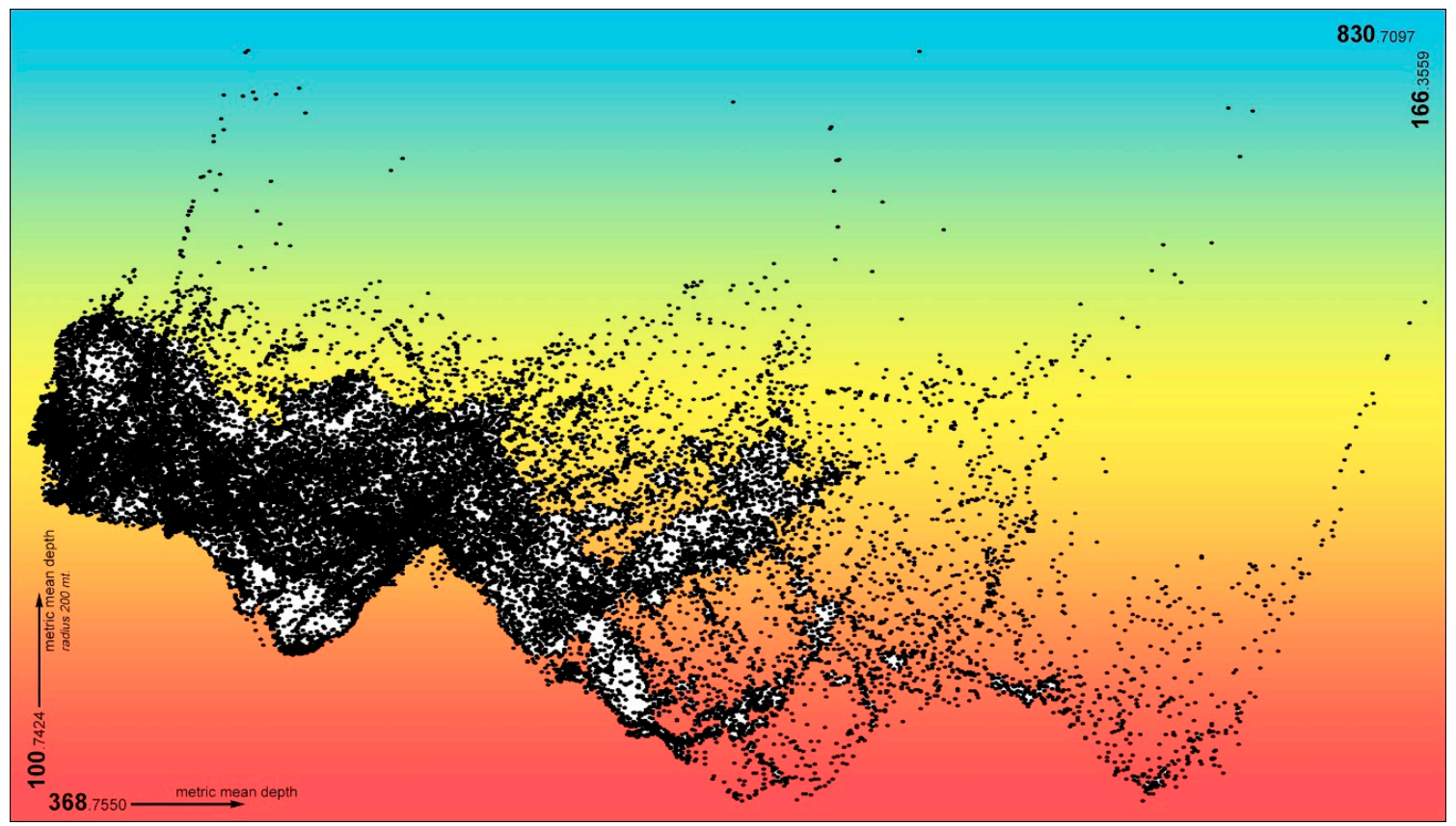

Figure 5. Background patchwork analysis (BPA) of BaSECo-local metric mean depth $200 \mathrm{~m}$. Labels on corners show upper and lower limits of indices values.

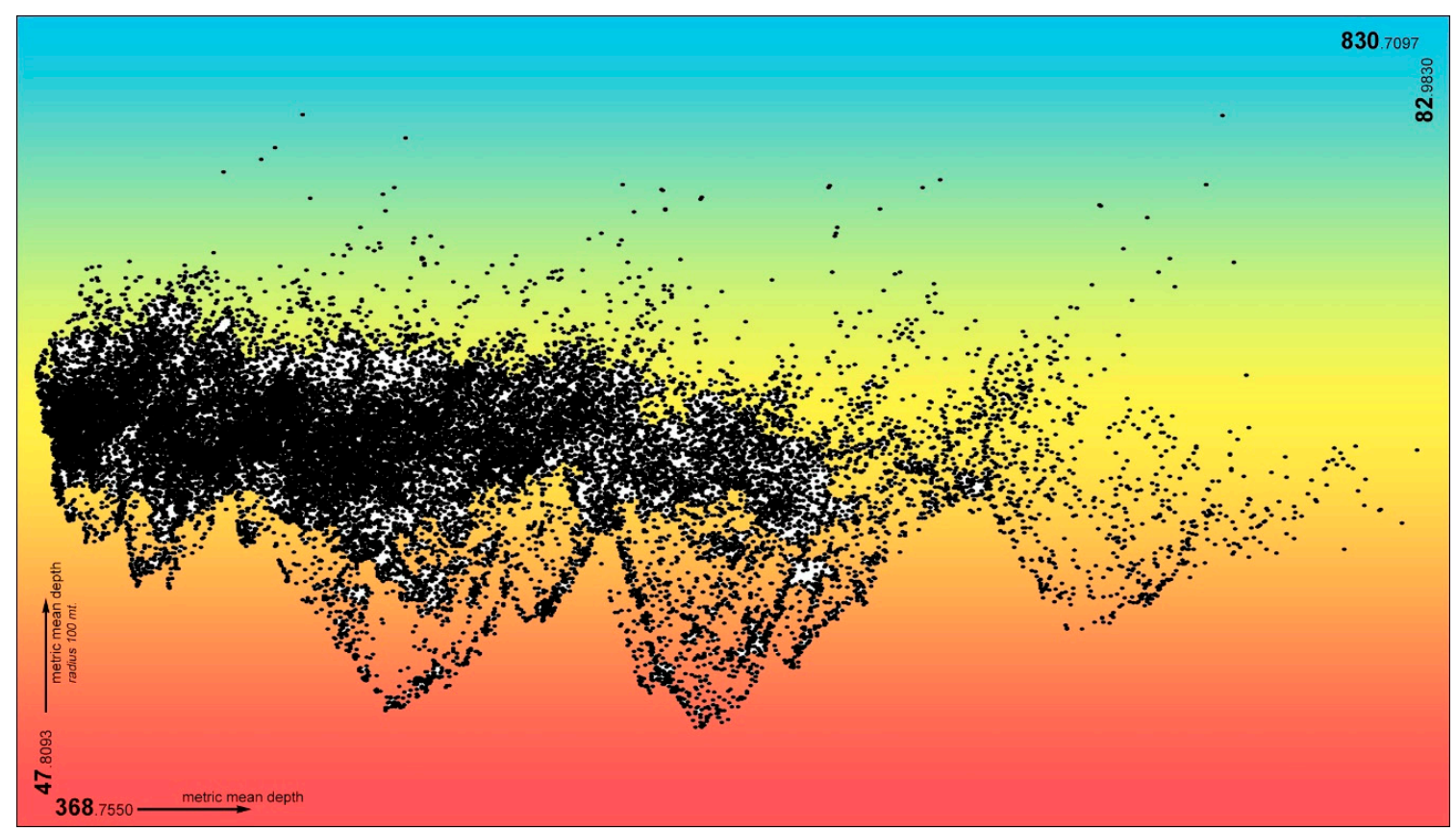

Figure 6. Background patchwork analysis (BPA) of BaSECo-local metric mean depth $100 \mathrm{~m}$. Labels on corners show upper and lower limits of indices values.

Referring to what was observed above, the configurational analysis highlights deep differences among urban districts due to their layout and, hence, the way people use the urban space. Thus, we take into account the urban district named New Site (NS) (Figure 8a) in the north-eastern part of the settlement and the district named OS(S) (Figure 8a) in the south. These two districts are paradigmatic for the case, by means of the compliance or defiance with urban archetypes. 


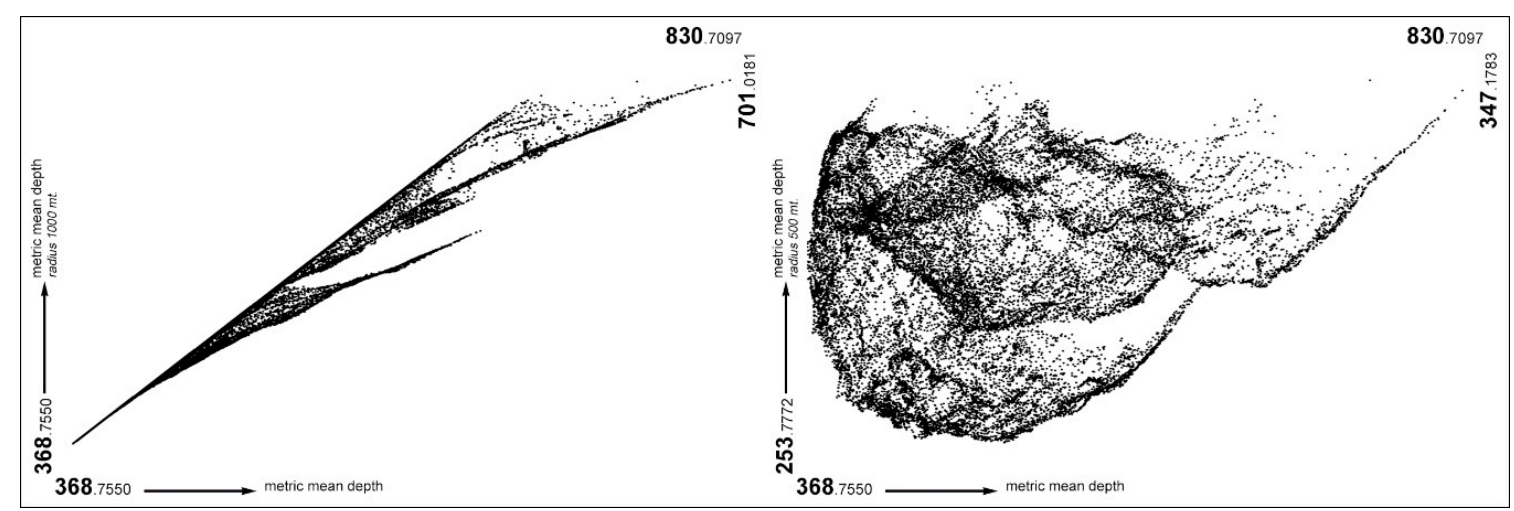

Figure 7. Background patchwork analysis (BPA) of BaSECo-local metric mean depth $1000 \mathrm{~m}$ (left) and $500 \mathrm{~m}$ (right). Labels on corners show upper and lower limits of indices values.

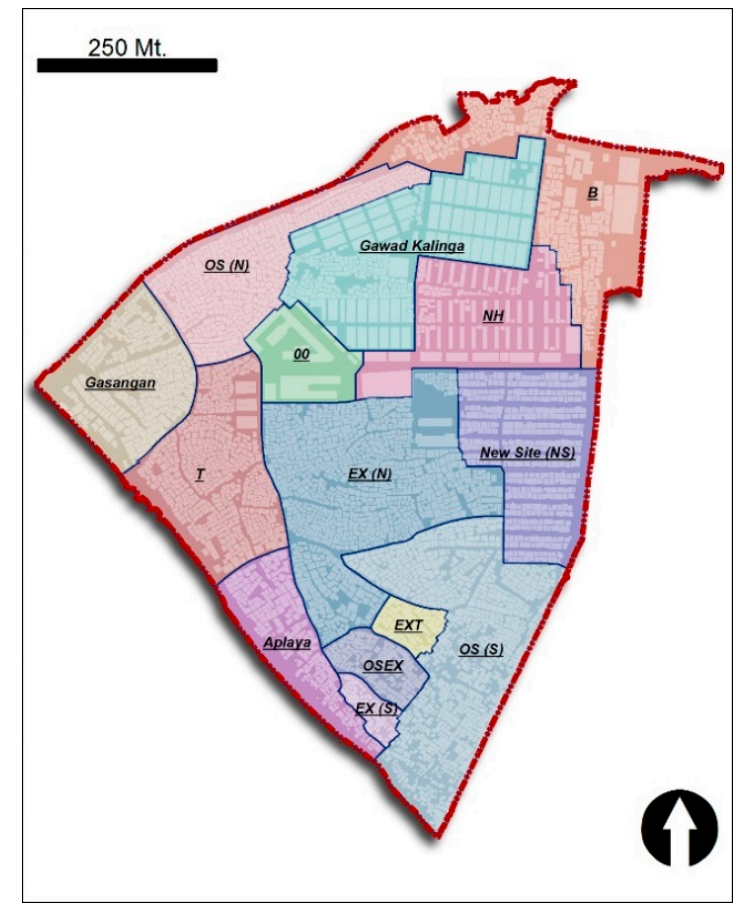

(a)

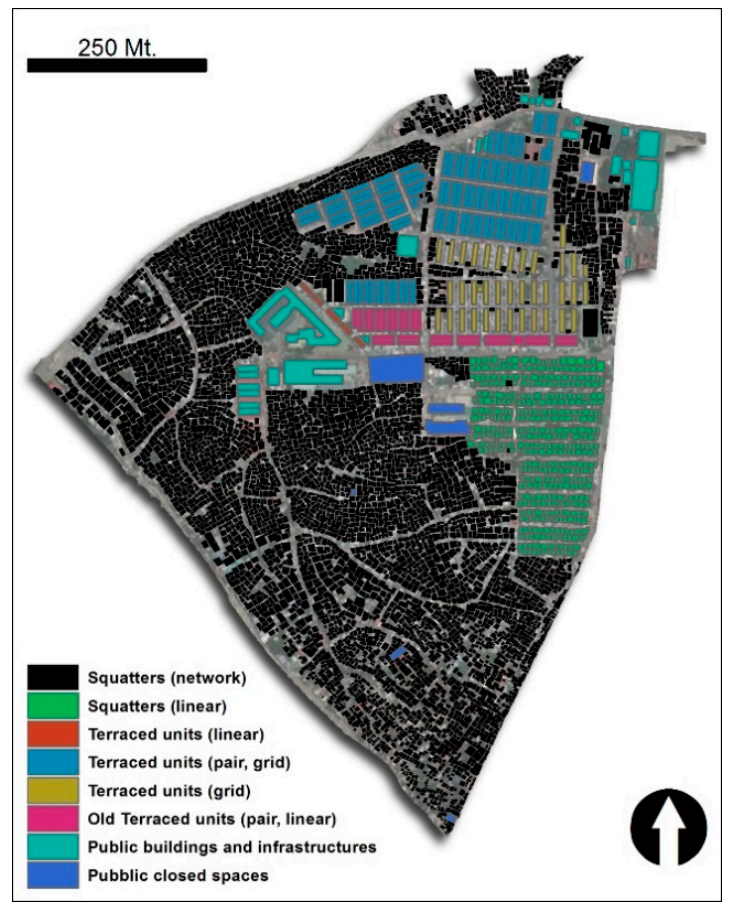

(b)

Figure 8. Urban morphology in BaSECo: (a) urban districts; (b) building types and related morphology (if relevant).

NS is characterized by a purely linear layout, arose after a major catastrophic fire event occurred some years ago, which moved institutions to implement a planned reconstruction. By contrast, OS(S) hosts one of the largest organic patterns of BaSECo, unaffected by formal planning activities and neglecting any intelligible layout.

As a result, although both districts present high values of local integration (Figure 4), in NS, there is a regular decreasing gradient from peaks, while segregated lines are almost missing. Conversely, in OS(S), the gradient is very steep, thus presenting a lot of peaks composed by few lines surrounded by many segregated lines. This is what the authors recognized as the configurational trace left by the spaces-in-between in the topology of the settlement. The configurational analysis thus identifies differences among urban districts, fostering the deep trace of their form in the topology of a connected urban network. 
As for the qualitative issues, the urban morphology of BaSECo is filled up to $40 \%$ by squatters and small, one- or two-story buildings. They are mainly organized in apparently chaotic patterns and constructed with recycled materials. If the largest part of the BaSECo buildings has no reference to geometrical schemes, some of them follow linear and orthogonal schemes, resulting from the few planning actions implemented in the last few years. Generally, they overlook paved roads, and, albeit never exceeding two floors and provided with minimal plant equipment, present a higher build quality. A small set of infrastructures, polarized in the northern edge of the settlement, complete the neighborhood, composed of the only real buildings in BaSECo for what concerns construction technology and equipment. The building types, urban morphology, and topological dynamics of the settlement are therefore strictly related. Even though the largest part of BaSECo grew up without any reference to schemes, rules, and urban design, to date, the system of the main roads appears to define a large pattern of homogeneous buildings. Despite the fact that most of them should be counted as squatters, those buildings differ substantially from each other with reference to the date of construction, thus being similar, but non-coincident, in terms of materials, arrangements, and spacing.

A brief analysis of the evolution of the settlement in the last decade shows that the limits of urban morphological areas in BaSECo followed the autopoietic use of new land made available by the expansion of the waste heap that formed the foundation of the settlement (Figure 1).

The inner logic of BaSECo makes the limits of its districts and the system of its main roads almost coincide, relegating them as a background in the evolution of the urban system, which appears marked by the presence of several local clusters of buildings. This seems to be generally consistent with the findings of the configurational analysis (Figures 8 and 9).

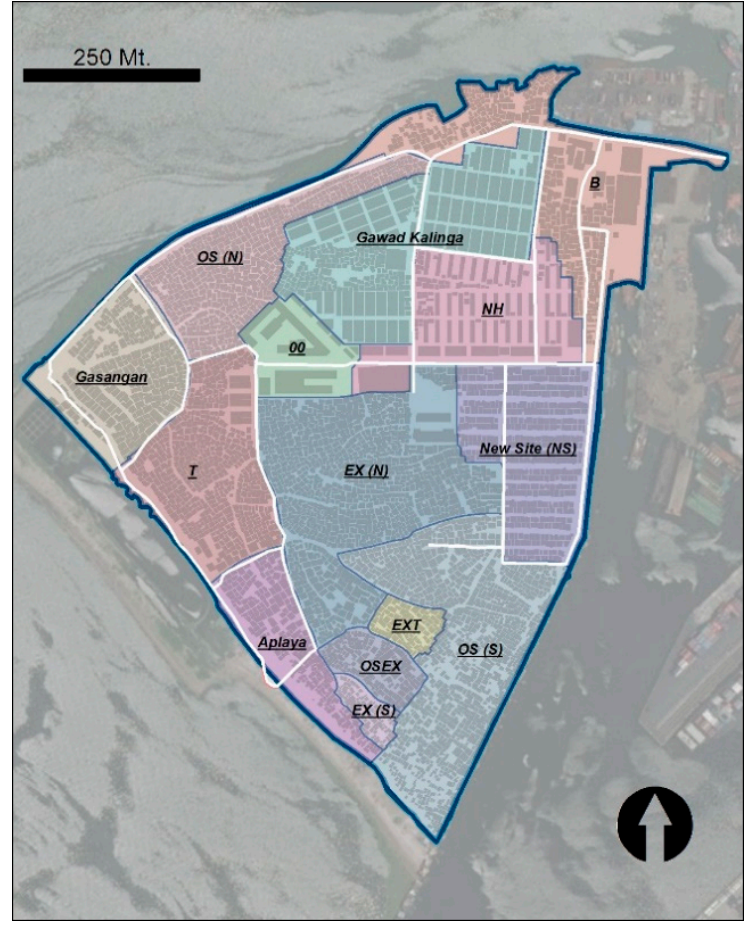

(a)

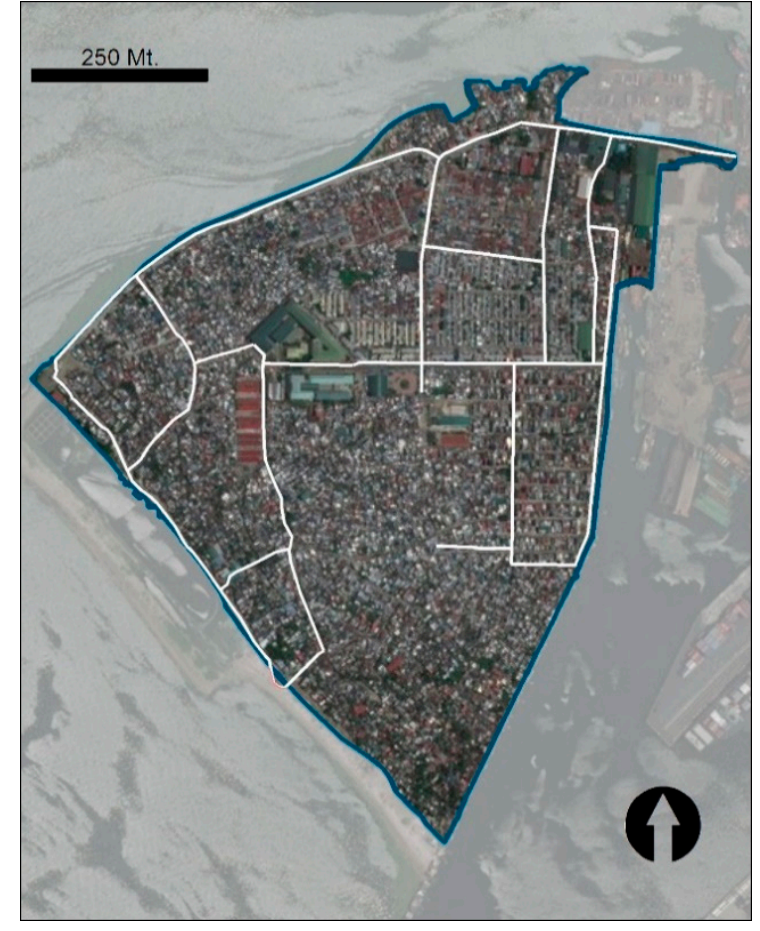

(b)

Figure 9. The main roads in BaSECo overlaid on urban districts (a) and a satellite image (b)

Summing up, the settlement of BaSECo is generally characterized by low standards in terms of construction quality and services, according to a spatial hierarchy that appears fully consistent with the taxonomy depicted by the configuration analysis. Most of higher quality and better serviced buildings are located along the main roads in the centre of the settlement, which configurational analysis gathers into the foreground structure of the whole system. The squatter buildings, on the contrary, are 
well away from the geometric center of the settlement, flourishing where spaces-in-between are the dominating urban element, as space syntax shows by means of local measures of centrality. The most serious features of informality increasingly arise, moving away from the most integrated lines at a global level. In the south of the settlement, where urban expansion is newer and segregation sharpened, the overall quality of buildings and life standards are lower than in the north. This is actually consistent with the definition of informal society and confirmed by a preliminary analysis of BaSECo population annual income. An in-person survey on families living in different urban districts of BaSECo (Figure 8a) confirms that moving from Gawad Kalinga to New Site to the OS(S) district, residents' annual income tends to significantly decrease. Extensive results of this research are still unpublished [60].

Form and function in BaSECo seem therefore to be more consistent than can be perceived, suggesting the idea that in informal, non-regulated, and autopoietic urban systems, some deep inner rules appear to govern the genesis and the dynamics of the settlements.

\section{Discussion of Results and Conclusions}

The quantitative and qualitative analysis of BaSECo properly confirms the expectations pointed out in the introduction. The lack of a visual archetype in the form of the largest part of the settlement structure is balanced by the presence, in the topology of those areas, of a large set of small local centralities, resulting in what we call a "chaotic order": BaSECo seems, hence, to be apart from what urban science traditionally collects as a predictable urban phenomenon, unless its inner logic is observed as a complex urban network.

The order in BaSECo is driven by the set of what we call spaces-in-between: a set of urban elements characterized by peaks in local integration surrounded by locally segregated lines with a fast decreasing gradient. These urban units cannot be precisely located on the urban network due to their fuzzy character, as highlighted by the distribution of topological local integration, which proved to be a good predictor of pedestrian movement on urban network, so as to numerically express how people move and navigate within the city. It reflects the idea of BaSECo as a "proximal settlement" made of a very high number of tiny individual neighborhoods, interacting with one another to create a complex cloud with soft and uncertain borders. This local urban structure has been regarded as a distinctive trait of BaSECo, just like its global structure that seems to only vaguely support the functioning of the urban system, lacking a significant centrality all over the whole settlement.

This is also proved by a low value of the synergy index (0.3562), the $\mathrm{R}^{2}$ value of the correlation of local integration at three steps with global integration, which expresses how narrowly the local neighborhoods of a settlement relate to the global system [31]. Low values of synergy index, as in this case, suggest that movement at a local scale does not provide useful information on global structures, making dominant the individual experience at the small-scale neighborhoods composing the patchwork of the settlement.

Such findings are overall confirmed by qualitative analysis, both in terms of urban morphology and building features, such as construction materials and building typologies. A narrow relationship between qualitative features and topological properties of urban environment arises, which attests to the local integration index as a good indicator of the main social and physical features of BaSECo. In the frame of the notion of proximal city, it also seems to reveal that walkability has actually driven its development and ruled its dynamics.

Aside from the specific case, more than one billion people live in slums, which is to say almost $32 \%$ of the worldwide urban population [61]. One of the most important tasks for the urban agenda of the next decade is to take on this critical issue, planning the redevelopment of these settlements without the displacing of the present inhabitants. According to the idea introduced in the late 1970s by the British architect John Turner, slums need to be considered as a solution more than a problem, due to their adaptable constructive solutions as well to their resilient and supportive society [62]. A recent approach turns Turner's idea in the so-called "on-site upgrading strategies," proposing the 
development of new houses, better streets and public spaces, and other facilities, minimizing the relocation of inhabitants and avoiding gentrification.

In this frame, supporting an on-site approach means a better understanding of the inner dynamic of informal settlements and of informal society as well. The presented research, based on the comparison between quantitative and qualitative analysis, proposes a non-discursive methodology to provide a deep and easily accessible knowledge on both these domains. The paper highlights the effectiveness of the configurational approach in making the latent properties of what appears a chaotic urban space to arise. The proposed notion of the proximal city, which pivots on the configurational interpretation of walkability, seems to open promising perspectives in grasping some essentials of informal settlements. Further research is required to provide this notion with a more comprehensive conceptual definition and to more analytically define its qualitative and quantitative features.

Moreover, the implementation of the proposed methodology on the case of BaSECo compound proved that tools pivoted on the integration of configurational theory and morphological analysis of the city can actually provide meaningful knowledge of the settlements, which is essential in any intervention strategy. This kind of tool seems suitable for supporting policy makers and urban designers in the development of regeneration strategies based on on-site schemes at different phases of urban design and master planning.

More reliable predictions on the effects of regeneration plans and projects on the functioning of the settlements, as well on the way the local communities use their spaces, are indeed paramount to minimize their failure chances; they can effectively avoid the controversial and undesirable effects of urban renewal (like gentrification) and maximize the positives (better quality of life, control of rents and property values, respect of local culture). At the same time, a deeper comprehension of the inner logic and hidden features of informal settlements actually fosters the adoption of regeneration strategies based on the exploitation of the local spatial resources and bottom-up processes. Furthermore, improving control on regeneration effects supports decision processes, as well as a better use of public and private resources.

In a broader perspective, the proposed notion of proximal city, here introduced and applied to the issue of the urban regeneration of informal settlements, seems a promising concept to be further discussed and developed for the interpretation of autopoietic urban systems. In this regard, some further research is needed both in theoretical and experimental terms in order to provide a more robust definition that pivots on non-discursive features and a larger record of case studies.

Author Contributions: Conceptualization, V.C., V.D.P., A.M.R., and F.R.; Methodology, V.C., V.D.P., A.M.R., and F.R.; Investigation, V.C., V.D.P., A.M.R., and F.R.; Formal Analysis, V.D.P.; Writing-original draft, V.C. and V.D.P.; Writing-review and editing, V.C., V.D.P., A.M.R., and F.R. All authors have read and agreed to the published version of the manuscript.

Funding: This research was funded by the University of Pisa Research Project PRA_2018_35 “Approcci ecosostenibili per i sistemi idrici e la riqualificazione del territorio in ambito urbano."

Conflicts of Interest: The authors declare no conflict of interest.

\section{References}

1. UN-Habitat. Habitat III Issue Papers 22 Informal Settlements; UN-Habitat: New York, NY, USA, 2015.

2. UN-Habitat. The State of the World Cities Report 2012/13; Routledge: New York, NY, USA, 2013.

3. Cutini, V.; Di Pinto, V. Informal settlements, complexity and urban models: Is there any order in autopoietic urban systems? In Environmental and Territorial Modelling for Planning and Design; Leone, A., Gargiulo, C., Eds.; FedOAPress: Naples, Italy, 2018.

4. Cutini, V.; Di Pinto, V.; Rossini, F. At the border of the city. A preliminary study to an evidence-based approach to informal settlements. Urban. Inf. 2017, 272, 31-35.

5. Karimi, K.; Parham, E. An evidence informed approach to developing an adaptable regeneration programme for declining informal settlements. In Proceedings of the 8th International Space Syntax Symposium, Santiago, Chile, 3-6 January 2012. 
6. Hutabarat Lo, R. Walkability: What is it? J. Urban. 2009, 2, 145-166. [CrossRef]

7. Ewing, R.; Handy, S. Measuring the Unmeasurable: Urban Design Qualities Related to Walkability. J. Urban Des. 2009, 14, 65-84. [CrossRef]

8. Li, X.; Ratti, C.; Seiferling, I. Mapping urban landscapes along streets using Google Street View. In Advances in Cartography and GIScience: Selections from the International Cartographic Conference 2017; Peterson, M.P., Ed.; Springer: Berlin, Germany, 2017; pp. 341-356.

9. Miller, H.J.; Tolle, K. Big data for healthy cities: Using location-aware technologies, open data and 3D urban models to design healthier built environments. Built Environ. 2016, 42, 441-456. [CrossRef]

10. Li, X.; Santi, P.; Courtney, T.K.; Verma, S.K.; Ratti, C. Investigating the association between streetscapes and human walking activities using Google Street View and human trajectory data. Trans. GIS 2018, 22, 1029-1044. [CrossRef]

11. Badland, H.M.; Schofield, G.M.; Garrett, N. Travel behavior and objectively measured urban design variables: Associations for adults traveling to work. Healt Place 2008, 14, 85-95. [CrossRef] [PubMed]

12. Koohsari, M.J.; Sugiyama, T.; Lamb, K.E.; Villanueva, K.; Owen, N. Street connectivity and walking for transport: Role of neighborhood destinations. Prev. Med. 2014, 66, 118-122. [CrossRef]

13. Raford, N.; Ragland, D. Space Syntax: Innovative Pedestrian Volume Modeling Tool for Pedestrian Safety. Transp. Res. Rec. J. Transp. Res. Board 2004, 1878, 66-74. [CrossRef]

14. Hillier, B.; Penn, A.; Hanson, J.; Grajewski, T.; Xu, J. Natural movement: Or, configuration and attraction in urban pedestrian movement. Environ. Plan. B Plan. Des. 1993, 20, 29-66. [CrossRef]

15. Rossini, F.; Rinaldi, A.; Di Pinto, V. Public spaces and critical density, a preliminary study proposal for Baseco informal settlement in manila. In Proceedings of the XXIV ISUF International Conference: City and Territory in the Globalization Age, Valencia, Spain, 27-29 September 2017.

16. Roy, A. Urban Informality: Toward an Epistemology of Planning. J. Am. Plan. Assoc. 2005, 71, 147-158. [CrossRef]

17. Roy, A.; AlSayyad, N. Urban Informality: Transnational Perspectives from the Middle East, South Asia and Latin America; Lexington Books: Lanham, MD, USA, 2004.

18. Aguilar, A.; Ward, P. Globalization, regional development and mega-city expansion in Latin America: Analyzing Mexico City's peri-urban hinterland. Cities 2003, 20, 3-21. [CrossRef]

19. McGee, T.G. The emergence of desakota regions in Asia: Expanding a hypothesis. In The Extended Metropolis: Settlement Transition in Asia; Ginsburg, N., Koppel, B., McGee, T.G., Eds.; University of Hawaii Press: Honolulu, HI, USA, 1991.

20. Bayat, A.; Denis, E. Who is afraid of ashwaiyyat? Urban change and politics in Egypt. Environ. Urban. 2000, 12, 185-199.

21. Jones, G.; Ward, P. Privatizing the commons: Reforming the ejido and urban development in Mexico. Int. J. Urban Reg. Res. 1998, 22, 76-93. [CrossRef]

22. Soliman, A. Tilting at sphinxes: Locating urban informality in Egyptian cities. In Urban Informality: Transnational Perspectives from the Middle East, South Asia and Latin America; Roy, A., AlSayyad, N., Eds.; Lexington Books: Lanham, MD, USA, 2004.

23. Boyer, M.C. On Modelling Complexity and Urban Form. Archit. Des. 2015, 85, 54-59. [CrossRef]

24. Jones, P. The Shaping of Form and Structure in Informal Settlements: A Case Study of Order and Rules in Lebak Siliwangi, Bandung, Indonesia. J. Reg. City Plan. 2019, 30, 43-61. [CrossRef]

25. Cutini, V.; Di Pinto, V.; Rinaldi, A.; Rossini, F. Informal Settlements Spatial Analysis Using Space Syntax and Geographic Information Systems. In Lecture Notes in Computer Science; Misra, S., Gervasi, O., Murgante, M., Stankova, E., Korkhov, V., Torre, C., Rocha, A., Taniar, D., Apduhan, O., Tarantino, E., Eds.; Springer: Cham, Switzerland, 2019; Volume 11621.

26. Habib-Mintz, N. To what Extent can the Informal Economy Concept Adequately Explain the Dynamism of the Non-Formal Sector in Developing Countries? J. Int. Bus. Econ. 2009, 10, 1-19.

27. UN-Habitat. The State of Asia Cities 2010/11; UN-HABITAT—Regional Office for Asia and the Pacific: Fukuoka, Japan, 2011.

28. UN-Habitat. Citywide Slum Upgrading — Low Carbon Green Growth Roadmap for Asia and the Pacific-Fact Sheet; UN-HABITAT—Regional Office for Asia and the Pacific: Fukuoka, Japan, 2011.

29. Hillier, B.; Hanson, J. The Social Logic of Space; Cambridge University Press: Cambridge, UK, 1984.

30. Hillier, B. Cities and movement economies. Urban Des. Int. 1996, 1, 41-60. [CrossRef] 
31. Hillier, B. Space is the Machine; Cambridge University Press: Cambridge, UK, 1996.

32. Middleton. Walking in the City: The Geographies of Everyday Pedestrian Practices. Geography Compass 2011, 5, 90-105. [CrossRef]

33. Baran, P.K.; Rodríguez, D.A.; Khattak, A.J. Space Syntax and Walking in a New Urbanist and Suburban Neighbourhoods. J. Urban Des. 2008, 13, 5-28. [CrossRef]

34. Talav Era, R. Improving pedestrian accessibility to public space through Space Syntax analysis. In Proceedings of the 8th International Space Syntax Symposium, Santiago, Chile, 3-6 January 2012.

35. Peponis, J.; Hadijnkolaou, E.; Livieratos, C.; Fatouros, D.A. The spatial core of urban. Ekistics 1989, 56, 43-55.

36. Hillier, B.; Burdett, R.; Peponis, J.; Penn, A. Creating life: Or, does architecture determine anything? Arch. Comport./Arch. Behav. 1987, 3, 233-250.

37. Monokrousou, K.; Giannopoulou, M. Interpreting and Predicting Pedestrian Movement in Public Space through Space Syntax Analysis. Procedia Soc. Behav. Sci. 2016, 223, 509-514. [CrossRef]

38. Al Sayed, K.; Turner, A.; Hillier, B.; Iida, S.; Penn, A. Space Syntax Methodology, 4th ed.; Bartlett School of Architecture-UCL: London, UK, 2014.

39. Turner, A. Angular Analysis. In Proceedings of the 3rd International Space Syntax Symposium, Atlanta, GA, USA, 7-11 May 2001.

40. Turner, A. Depthmap 4: A Researcher's Handbook; University College London: London, UK, 2004.

41. Vaughan, L. The spatial syntax of urban segregation. Prog. Plan. 2007, 67, 205-294. [CrossRef]

42. Porta, S.; Crucitti, P.; Latora, V. The network analysis of urban streets: A dual approach. Phys. A Stat. Mech. Appl. 2006, 369, 853-866. [CrossRef]

43. Jiang, B. Ranking spaces for predicting human movement in an urban environment. Int. J. Geogr. Inf. Sci. 2009, 23, 823-837. [CrossRef]

44. Sole, R.; Valverde, S. Information Theory of Complex Networks: On Evolution and Architectural Constraints. In Lecture Notes in Physics; Ben-Naim, E., Frauenfelder, H., Toroczkai, Z., Eds.; Springer: Berlin/Heidelberg, Germany, 2004; Volume 650. [CrossRef]

45. van Nes, A.; Yamu, C. Space syntax: A method to measure urban space related to social, economic and cognitive factors. In The Virtual And The Real in Planning and Urban Design: Perspectives, Practices and Applications; Yamu, C., Poplin, A., Devisch, O., de Roo, G., Eds.; Routledge: Oxon, UK; New York, NY, USA, 2018. [CrossRef]

46. Porta, S.; Crucitti, P.; Latora, V. The Network Analysis of Urban Streets: A Primal Approach. Environ. Plan. B Plan. Des. 2006, 23, 705-725. [CrossRef]

47. Turner, A. An algorithmic definition of the axial map. Environ. Plan. B Plan. Des. 2005, 32, 425-444. [CrossRef]

48. Varoudis, T. Depthmap X Multi-Platform Spatial Network Analysis Software, Version 0.50. Available online: http://varoudis.github.io/depthmapX/ (accessed on 29 September 2019).

49. Varoudis, T. DepthmapXnet-Version 0.35. 2017. Available online: http://archtech.gr/varoudis/depthmapX/ ?dir=depthmapXnet (accessed on 29 September 2019).

50. Space Syntax Software. Available online: http://www.spacesyntax.net/software/ (accessed on 29 September 2019).

51. ArcGIS Desktop. Available online: http://desktop.arcgis.com/en/ (accessed on 29 September 2019).

52. Ortega, A.A.C. Mapping Manila's Mega-Urban Region. Asian Popul. Stud. 2014, 10, 208-235. [CrossRef]

53. Philippine Statistic Authority: Highlights of the Philippine Population 2015 Census of Population. Available online: https://psa.gov.ph/content/highlights-philippine-population-2015-census-population (accessed on 29 September 2019).

54. Galuszka, J. Community-based approaches to settlement upgrading as manifested through the big ACCA projects in Metro Manila, Philippines. Environ. Urban. 2014, 26, 276-296. [CrossRef]

55. Rubin, D.; Oman, R.; Videcnik, S. Manila: Future Habitations; Harvard University Graduate School of Design: Cambridge, MA, USA, 2018.

56. Rossini, F. Architectural Interventions in the Informal City: On-site Upgrading Strategies for BaSECo Community. In Proceedings of the 34th International Conference on Passive and Low Energy Architecture (PLEA 2018), Hong Kong, China, 10-12 December 2018.

57. Hernández-García, J. Public Space in Informal Settlements: The Barrios of Bogotá; Cambridge Scholars Publishing: Cambridge, UK, 2013.

58. Hillier, B. The architecture of urban object. Ekistic 1989, 56, 5-21. 
59. Monokrousou, K.; Giannopoulou, M. Interpreting and Predicting Pedestrian Movement in Public Space through Space Syntax Analysis. In Procedia—Social and Behavioral Sciences; Calabrò, F., Della Spina, L., Eds.; Elsevier B.V.: Amsterdam, The Netherlands, 2016; Volume 223.

60. Rossini, F. The Chinese University of Hong Kong-School of Architecture-Student's Workshop on Baseco Compound-Draft Booklets. 2018, unpublished.

61. UN-Habitat. The Challenge of Slums, Global Report on Human Settlements 2003; Earthscan Publications Ltd.: London, UK, 2003.

62. Turner, J.F.C.; Fichter, R. Freedom to Build: Dweller Control of the Housing Process; The Macmillan Company: New York, NY, USA, 1972.

(C) 2020 by the authors. Licensee MDPI, Basel, Switzerland. This article is an open access article distributed under the terms and conditions of the Creative Commons Attribution (CC BY) license (http://creativecommons.org/licenses/by/4.0/). 